Aline TeiXerRa Alves'

RAque HenRIQUes JácOMO²

LIANA BARBARESCO GOMIDE ${ }^{1}$

Patrícia AzeVedo Garcia ${ }^{1}$

Albênica Paulino dos Santos Bontempo ${ }^{3}$

Margô Gomes de Olivera KarNIKOSKWi ${ }^{4}$

\title{
Relationship between anxiety and overactive bladder syndrome in older women
}

\author{
Relação entre ansiedade e sindrome da bexiga hiperativa em \\ mulheres mais velhas
}

Original Article

Keywords

Abstract

Urinary bladder, overactive

Anxiety

Aged

Palavras-chave

Bexiga urinária hiperativa

Ansiedade

Idoso

PURPOSE: The objective of this study was to investigate the relationship between overactive bladder syndrome and anxiety in older women. METHODS: Of the 198 older women who were invited, 29 were excluded and 166 were then divided into two groups according to the Advanced Questionnaire of Overactive Bladder (OAB-V8): one group with overactive bladder symptoms $(O A B-V 8 \geq 8)$ and the other without the symptoms of an overactive bladder $(O A B-V 8<8)$. The purpose was to conduct a frequency analysis and to investigate the relation of the social demographic data and anxiety in the two groups. The Beck Anxiety Inventory (BAll) was used to evaluate the level of anxiety. The Kolmogorov-Smirnov test was used to determine the distribution of the data. The differences between the two groups for the continuous variables were analyzed by the Mann-Whitney $U$ test, the differences for the categorical variables were analyzed by the Chi-Square test and the association between the continuous variables was analyzed by the Spearman Correlation test. The tests were two-tailed with a confidence level of 5\%. RESULTS: Overall, the frequency of an overactive bladder was present in $117(70.5 \%)$ of the participants. The body mass index (BMI) of the group with overactive bladder symptoms was significantly higher than the $B M l$ of those without these symptoms ( $p=0.001)$. A higher prevalence of mild, moderate and severe anxiety was observed among older women with overactive bladder symptoms. In addition, the overactive bladder symptoms group presented a positive low correlation with anxiety symptoms $(r=0.345)$ and with $B M I(r=0.281)$. There was a small correlation between $\mathrm{BMI}$ and anxiety symptoms (r=0.164). CONCLUSIONS: Overactive bladder syndrome was prevalent among older women and the existence of these symptoms was linked to the presence of mild, moderate and/or severe anxiety symptoms.

\section{Resumo}

OBJETIVO: Investigar a relação entre a síndrome da bexiga hiperativa e ansiedade em mulheres mais velhas. MÉTODOS: Das 198 mulheres mais velhas que foram convidadas, 29 foram excluídas, restando 166, que foram divididas em dois grupos de acordo com o Questionário Avançado de Bexiga Hiperativa (OAB-V8): um grupo com sintomas de bexiga hiperativa (OAB-V8 88 ) e outro sem os sintomas da bexiga hiperativa (OAB-V8<8). $\bigcirc$ objetivo foi realizar uma análise de frequência e investigar a relação entre os dados sócio-demográficos e ansiedade entre os grupos. A Escala de Ansiedade de Beck (EAB) foi utilizada para avaliar o nível de ansiedade. O teste de Kolmogorov-Smirnov foi utilizado para determinar a distribuição dos dados. As diferenças entre os dois grupos para as variáveis contínuas foram analisadas pelo teste de MannWhitney, e para as variáveis categóricas foi utilizado o teste Qui-quadrado. Para analisar a associação entre as variáveis contínuas, foi utilizado o teste de Correlação de Spearman. Os testes foram bi-caudais com um nível de confiança de $5 \%$. RESULTADOS: Em geral, a frequência de bexiga hiperativa estava presente em $117(70,5 \%)$ das participantes. $\bigcirc$ grupo com sintomas de bexiga hiperativa apresentou um IMC (índice de massa corporal) significativamente maior do que aqueles sem esses sintomas $(p=0,001)$. Observou-se maior prevalência de ansiedade leve, moderada e grave entre as mulheres mais velhas com sintomas de bexiga hiperativa. Além disso, o grupo com sintomas de bexiga hiperativa apresentou correlação positiva baixa com sintomas de ansiedade $(r=0,345)$ e com o IMC (r=0,281). Houve uma pequena correlação entre IMC e sintomas de ansiedade $(r=0,164)$. CONCLUSÕES: Síndrome da bexiga hiperativa foi frequente entre as mulheres mais velhas e a existência desses sintomas estavam ligados à presença de sintomas de ansiedade leve, moderada e/ou grave.

Correspondence

Aline Teixeira Alves Universiddade de Brosilio - Foculdade de Ceilândia, Centro Metropolitano, Coniunto A Lote 01 - Ceilândia Sul. CEP: $72220-900$

Brasilia (DF), Brazi

Received $04 / 25 / 2014$

Accepted with modifications $06 / 09 / 2014$
Universidade de Brasilia - UnB - Brasilia (DF), Brazil.

'Physiotherapy Course, Universidade de Brasília - UnB - Brasília (DF), Brazil.

${ }^{2}$ Hospital Universitário de Brasília, Universidade de Brasília - UnB - Brasilia (DF), Brazil.

${ }^{3}$ Instituição de Educação Superior Santana - IESSA - Brasília (DF), Brazil.

4Pharmacy Course, Universidade de Brasília - UnB - Brasília (DF), Brazil.

Conflict of interests: none. 


\section{Introduction}

The overactive bladder syndrome $(\mathrm{OAB})$ is a clinical syndrome characterized by the urgent voiding with or without urge incontinence. It is usually associated with pollakiuria and nocturia in the absence of infection in the urinary tract or other evident pathology ${ }^{1,2}$. OAB is a common incapacitating condition that greatly affects the quality of life of individuals with the syndrome and is the second largest cause of urinary incontinence (UI) in women ${ }^{2}$. Women are usually more affected by this syndrome than men. One in four women has some complaints of lower urinary tract symptoms throughout their life and 20 to $30 \%$ of those are over the age of $55^{3}$. A Brazilian population-based study, conducted on middle-aged women, observed the prevalence of $18.9 \%$ of OAB symptoms ${ }^{4}$. Among the elderly, the presence of UI is a very common health problem ${ }^{3,5}$.

$\mathrm{OAB}$ is an important public health concern. Its high prevalence, in addition to the physical, economic, psychic, emotional, sexual and social impact in a woman's life, reflects on the health condition and directly interferes with the quality of their lives ${ }^{6,7}$. Despite its high impact on the quality of life, the dysfunctions of the urinary tract are most of the time neglected and underestimated ${ }^{8,9}$. Psychological variables, such as anxiety and depression, have been associated with urgency and urge incontinence symptoms and with other specific incontinence symptoms. Some investigators have suggested that psychosomatic disorders, such as anxiety, may play a role in the pathogenesis of $\mathrm{OAB}^{10}$. Anxiety is defined as a state characterized by the perception or interpretation of an event as threatening, which can manifest itself both physically as well as psychologically, and directly affects the health, well-being and quality of life of elderly people ${ }^{11,12}$. Although it is inconclusive that anxiety is the cause or consequence of $\mathrm{OAB}$, it is believed that there is a connection between the two. However, more studies are needed to understand this relationship ${ }^{12,13}$.

The prevalence and the relationship between $\mathrm{OAB}$ and other pathologies are unclear. Studies have investigated the symptoms using different types of instruments, forms of registering the data and different criteria to define $\mathrm{OAB}$, in addition to a non-homogenous population. In this context, the objective of this study was to investigate the relationship between overactive bladder syndrome and anxiety in older women.

\section{Methods}

Subject screening was conducted in older women that lived in the community and attended the elderly health awareness program in Ceilândia, Distrito Federal Brazil, that was established by the fire brigade between August of 2012 and November of 2013. The criteria for eligibility were: female sex, age equal to or higher than 60 years, and without lower urinary tract infection that were identified through a urine test (urine culture) associated to the evaluation of symptoms (beginning of the study). Older women with a history of treatment for OAB and/ or anxiety in the last six months, history of neurological diseases (Multiple Sclerosis, Alzheimer Disease, Stroke, Parkinson's Disease), bladder cancer (hematuria and/or account), complaints of pain in the lower part of the womb during voiding for more than six months (possible indication of interstitial cystitis), history of pelvic radiotherapy, presence of advance genital prolapse that goes beyond the vaginal introits at rest (physical exam) and incapacity to respond the questionnaire appropriately were excluded from the study. A sample size calculation was performed to analyze the correlation between the variable $\mathrm{OAB}$ and anxiety, using the G-Power Program — commonly used in social and behavioral research. A pilot study with 41 older women, with a $5 \%$ level of confidence and with power of $80 \%$, suggested a sample of 153 older women.

The Advanced Questionnaire of Overactive Bladder OAB-V8 (Overactive Bladder-Validated 8) was used to scan for OAB. This instrument was created to help individuals and health professionals identify overactive bladder symptoms and had been validated for the Brazilian population. It contained eight questions that investigated the frequency of diurnal voiding, three questions that investigated the urgency, two that investigated urge incontinence, one that investigated the nocturnal enuresis, and a final one that investigated the frequency of nocturnal voiding. The symptoms were evaluated using a Likert scale from 0 (nothing) to 5 (a lot), with a maximum score of 40 points. A total score of 8 or more was characterized as a probable dysfunction in the lower urinary $\operatorname{tract}^{14}$.

The Beck Anxiety Inventory (BAI) was used to evaluate the level of anxiety. It was composed of 21 items that evaluated different anxiety symptoms identified through questions on self-evaluation and perception of anxiety of the individuals during the last week. Scores from 0 to 7 were considered no anxiety, from 8 to 15 as mild level, 16 to 25 as moderate level and from 26 to 63 as severe level of anxiety ${ }^{15}$.

In order to collect clinical and demographic variables, a medical history was conducted with questions regarding age, weight, height, number of pregnancies, number of abortions, number of vaginal births, number of caesarian sections, medication, associated diseases, previous pelvic radiotherapy and symptoms of the lower urinary tract such as voiding pain, blood in the urine, high-pubic pain and sensation of incomplete bladder emptying. After consent form the participants, the interviews were scheduled through the Health Center of the region.

The procedures for women with absence of urinary infection, as shown by the urine culture, were conducted in 
the following order: first the structured questionnaire for the clinical and demographic variables were collected followed by the OAB-V8, the Beck Anxiety Inventory (BAI) and the physical exam for the evaluation of physical strength and genital prolapse. Women with infection in the lower urinary tract were referred to a doctor. After the data collection, women with $\mathrm{OAB}$ were referred to a specific treatment.

The present research was approved by the Ethics Committee of the College of Health Sciences of the University of Brasilia by the protocol number 410.161 on September $30^{\text {th }}, 2013$. All patients signed a free and informed consent and the study was conducted in accordance with the Declaration of Helsinki as revised in 2008.

For the continuous variables, the information collected was expressed in average and standard deviation. As for the categorical variables, the information was expressed in percentages and frequency. The distribution of the data was performed using the Kolmogorov-Smirnov test. The sample was divided into two groups, according to the presence of lower urinary tract dysfunction (overactive bladder) by the OAB-V8. The differences between the two groups for continuous variables were analyzed using the Mann-Whitney U test. For the categorical variables, the Qui-Square test was used. To analyze the association between the continuous variables, the Spearman Correlation test was used. The tests were twotailed with a confidence level of 5\%. The Statistical Package for Social Sciences Program with the 16.0 version was used.

A total of 198 patients were recruited and 7 had urinary tract infection identified on examination of the urine culture. 191 older women were considered eligible for the study and after the interview, 25 were excluded because of neurological diseases ( 7 Stroke, 1 Alzheimer's, 2 Parkinson), history of radiotherapy (1), reports of bladder cancer (1), prolapsed bladder grade IV (2), use of anxiolytic drug (7) or did not complete the questionnaire (4). Thus, analyses were conducted with 166 older women, above the sample size previous calculated.

\section{Results}

The frequency of women with $\mathrm{OAB}(\mathrm{OAB}-\mathrm{V} 8 \geq 8$ points) was $70.5 \%$ (117). The average score in the OAB-V8 between the older women that showed signs of dysfunction was 21.8 \pm 6.6 , and between those without the signs of an overactive bladder $(\mathrm{OAB}-\mathrm{V} 8<8)$ was $2.3 \pm 2.2$ points.

The clinical and demographic data of the groups with and without overactive bladder symptoms are shown in Table 1. The groups were similar in age $(\mathrm{p}=0.282)$, number of pregnancies $(\mathrm{p}=0.09)$, number of abortions $(\mathrm{p}=0.07)$ and number of vaginal births $(\mathrm{p}=0.089)$. However, older women with overactive bladder symptoms (OAB-V8 $\geq 8)$ presented a BMI significantly higher than those without the symptoms $(\mathrm{OAB}-\mathrm{V} 8<8)(\mathrm{p}=0.001)$.
In relation to the vaginal birth, no significant difference was found between groups $(p=0.343)$ for prevalence of women who denied vaginal birth and of women who reported one or more vaginal births. In relation to the occurrence of levels of anxiety (no anxiety, mild, moderate and severe) between the study groups, a higher prevalence of mild, moderate and severe anxiety was observed in women with overactive bladder symptoms (Table 2).

There was a small and positive correlation between the anxiety symptoms $(r=0.34)$ and BMI $(r=0.28)$ with the group that had overactive bladder symptoms (Table 3 ). A small correlation between BMI and anxiety symptoms $(r=0.16)$ was also observed.

Table 1. Clinical and demographic characteristics of the study groups

\begin{tabular}{lrrrrr}
\hline \multirow{2}{*}{ OAB-V8 $\geq 8$} & \multicolumn{4}{c}{ OAB-V8<8 } & \\
\cline { 2 - 5 } & \multicolumn{3}{c}{$\mathrm{n}=117$} & \multicolumn{3}{c}{$\mathrm{n}=49$} & p-value \\
\cline { 2 - 5 } & Mean & SD & Mean & SD & \\
\hline Age & 68.4 & 6.1 & 69.4 & 6.3 & 0.28 \\
BMI & 28.0 & 4.5 & 25.3 & 3.6 & 0.001 \\
Pregnancies & 4.9 & 3.4 & 5.8 & 3.0 & 0.09 \\
Abortions & 0.6 & 1.2 & 0.8 & 0.9 & 0.07 \\
Vaginal Births & 3.8 & 2.9 & 4.7 & 3.2 & 0.08 \\
\hline
\end{tabular}

Mann-Whitney U Test; OAB-V8: Overactive Bladder-Validated 8 question Screener; BMI: body mass index; SD: standard deviation

Table 2. Distribution of the data, number of pregnancies, vaginal births and anxiety, between the groups of elderly women

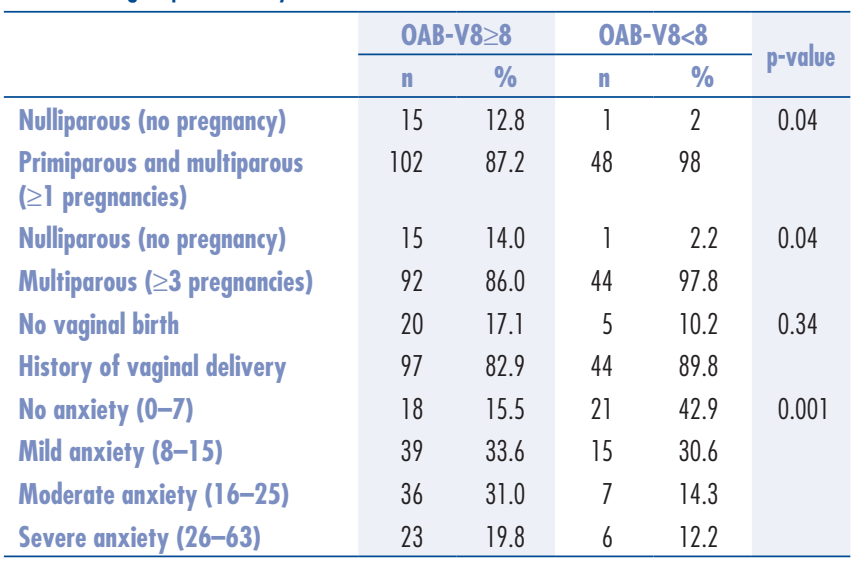

Qui-square test $\left(\chi^{2}\right)$; OAB-V8: Overactive Bladder-Validated 8 question Screener

Table 3. Correlation between the variables investigated in the study

\begin{tabular}{lcc}
\hline & OAB-V8 & Anxiety \\
\hline OAB-V8 & - & $0.34^{\star \star}$ \\
Anxiety & $0.34^{\star \star}$ & - \\
Age & -0.12 & -0.10 \\
BMI & $0.28^{\star \star}$ & $0.16^{\star}$ \\
Pregnancy & $-0.18^{\star}$ & -0.06 \\
Abortion & -0.11 & -0.02 \\
Vaginal Birth & $-0.17^{\star}$ & -0.07 \\
\hline
\end{tabular}

Spearman correlation coefficient $(r)$; ${ }^{*}<<0.05 ;{ }^{*} p<0.01 ; O A B-V 8$ : Overactive Bladder - Validated 8 question Screener/ BMI: Body Mass Index kg/m² 


\section{Discussion}

The present study applied the most current definition of OAB defined by the International Urogynecological Association and International Continence Society ${ }^{2}$. We found a high prevalence of overactive bladder symptoms $(70.5 \%)$ in older women living in the community. Taking into account the definition from $2002^{1}$, the European Prospective Investigation into Cancer and Nutrition (EPIC) study observed a minor prevalence of $\mathrm{OAB}$ in women $(12.8 \%)$ and in men $(10.8 \%)$ in Europe and Canada, possibly due to the lower age group studied (age $>18$ years $)^{16}$. The Brazilian Lower Urinary Tract Symptoms Epidemiology Study (BLUES), which investigated the symptoms of lower urinary tract in 3,000 individuals of both sexes with ages $\geq 30$ y.o. using the OAB-V8 instrument after some complaint of any overactive bladder symptom, found a prevalence of $\mathrm{OAB}$ in $5.1 \%$ of men and $10.0 \%$ of women. In addition, the study reinforced the fact that above 60 years of age, these rates are higher for both men (78\%) and women $(82 \%)^{17}$, corroborating the data found in the current study. Similar studies investigated the prevalence of $\mathrm{OAB}$ in elderly Americans and showed rates of $40.4 \%$ in men and $46.9 \%$ in women. In addition, the study reinforced the fact that this dysfunction has a great impact on the people's quality of life ${ }^{18}$.

When comparing clinical and demographic characteristics between the elders with and without overactive bladder symptoms, the only variable that showed signs of difference was the BMI, demonstrating that patients with $\mathrm{OAB}$ had a higher BMI than those without the symptoms. Additionally, the BMI showed a positive correlation with the results of the OAB-V8 questionnaire. A Brazilian study investigated the influence of $\mathrm{BMI}$ in $\mathrm{OAB}$ using urodynamic together with the King's Health Questionnaire (KHQ), which evaluates the OAB. No association was observed between $\mathrm{BMI}$ and the scores of the KHQ or with the urodynamic data, even in individuals that showed non-inhibited contractions of the detrusor or absence of detrusor contractions ${ }^{19}$. Despite the fact that several studies in the literature point to a direct relationship between the severity of the urinary incontinence to the level of obesity ${ }^{19,20}$, most of the results are still conflicting. In addition, most of the studies found evaluated loss of urine based on effort and not on OAB specifically.

It is well known that pregnancy is a risk factor recognized to stress urinary incontinence (SUI). Primiparous women have three times more the risk to develop SUI compared to nulliparous women when compared by age group $^{21}$. Recent evidence has shown that the type of birth also has a significant impact on SUI, showing that symptoms of SUI double in women who have at least one vaginal birth when compared to women who have had exclusively caesarian sections ${ }^{22}$. However, when the relation between birth and OAB was analyzed, it was observed that this association had not been well established in the literature, keeping in mind that the urge incontinence symptoms were reported in proportions similar to those between women who had vaginal births and nulliparous women ${ }^{21}$. Additionally, the risk for OAB in women, between 5-10 years after giving birth, was not significant when compared to the birthing methods (vaginal or caesarian section $)^{22}$. It is worth mentioning that the use of forceps during vaginal births could be associated with $\mathrm{OAB}^{21,22}$. These findings corroborate with our study, although a negative correlation was found between the OAB-V8 and the number of vaginal births and that no difference was found between the number of vaginal births between older women with or without OAB.

In relation to anxiety, it was observed that there was a higher frequency of mild, moderate and severe anxiety in women with OAB. Moreover, the anxiety symptoms showed a positive association with overactive bladder symptoms. These results corroborate the findings of other studies ${ }^{23,24}$ that found anxiety as a common manifestation in the elderly population (prevalence of up to $26 \%$ in people with 65 years or more), and whose prevalence increased in the presence of a chronic condition such as $\mathrm{UI}^{26,27}$. Several studies analyzed the association between urinary incontinence and anxiety symptoms. Lim et al. ${ }^{25}$ investigated anxiety symptoms between women with SUI and with mixed urinary incontinence and found that women with MUI had more anxiety when compared to women with just SUI. The authors emphasized the importance of the approach used when treating anxiety symptoms in patients with MUI. Similarly, Knight et al. ${ }^{26}$ found high levels of anxiety in women with $\mathrm{OAB}$ compared to women without this dysfunction. Other studies ${ }^{23,27}$ also found associations between anxiety symptoms, evaluated with the Hospital Anxiety and Depression Scale (HADS), and $\mathrm{OAB}$, evaluated by the 48-hour pad-test and through the questionnaire about urinary tract dysfunctions $(\mathrm{OAB}$ and frequency). The results indicated anxiety as risk factor for development of these symptoms ${ }^{26}$. Mehta et al. ${ }^{23}$ also investigated the relation of OBS with anxiety symptoms using the three items of the Symptom Checklist Hopkins, and, although a cause and effect relation could not be established, the authors concluded that individuals with $\mathrm{OAB}$ are more prone to anxiety symptoms.

The correlation findings of the present study, between BMI and anxiety, corroborate other studies ${ }^{28,29}$. It is important to consider that, although differences among studies $^{25-27}$ on the type of instruments used to evaluate anxiety and overactive bladder symptoms exist, the similar 
results support the use of $\mathrm{BAI}$ and $\mathrm{OAB}-\mathrm{V} 8$. However, these instruments are seldom described in the literature.

In conclusion, this study showed that $\mathrm{OAB}$ was highly prevalent among older women, and that women with overactive bladder symptoms also present mild, moderate and severe symptoms of anxiety.

\section{Acknowledgements}

This study was supported by the Center for Health 4 Ceilândia - DF in partnership with the Faculty of Ceilândia - Department of Physical Therapy, Universidade de Brasilia, Brazil.

\section{References}

1. Abrams P, Cardozo L, Fall M, Griffiths D, Rosier P, Ulmsten U, et al. The standardisation of terminology of lower urinary tract function: report from the Standardisation Sub-committee of the International Continence Society. Neurourol Urodyn. 2002;21(2):167-78.

2. Haylen B, Ridder D, Freeman RM, Swift SE, Berghmans B, Lee J, et al. An International Urogynecological Association (IUGA)/International Continence Society (ICS) joint report on the terminology for female pelvic floor dysfunction. Int Urogynecol J. 2010;21 (1):5-26.

3. Hu TW, Wagner TH, Bentkover JD, Leblanc K, Zhou SZ, Hunt TL. Costs of urinary incontinence and overactive bladder in the United States: a comparative study. Urology. 2004;63(3):461-5.

4. Teloken C, Caraver F, Weber FA, Teloken PE, Moraes JF, Sogari PR, et al. Overactive bladder: prevalence and implications in Brazil. Eur Urol. 2006;49(6): 1087-92.

5. Lazari IC, Lojudice DC, Marota AG. Avaliação da qualidade de vida de idosas com incontinência urinária: idosas institucionalizadas em uma instituição de longa permanência. Rev Bras Geriatr Gerontol. 2009;12(1):103-12.

6. Coyne KS, Zhou Z, Thompson C, Versi E. The impact on health-related quality of life of stress, urge and mixed urinary incontinence. BJU Int. 2003;92(7):731-5.

7. Griffiths $D$, Kondo A, Baver S, Diamant $N$, Liau $L$, Lose $G$, et al. Dynamic testing. In: Abrams P, Cardozo L, Koury S, Wen A, editors. Incontinence basic \& evaluation. Bristol: International Continence Society; 2005. p. 585-674.

8. Agnew R, Booth J. Promoting urinary continence with older people: a selective literature review. Int J Older People Nurs. 2009;4(1):58-62.

9. Ouslander JG, Abelson S. Perceptions of urinary incontinence among elderly outpatients. Gerontologist. 1990;30(3):369-72.

10. Freeman RM, McPherson FM, Baxby K. Psychological features of women with idiopathic detrus or instability. Urol Int. 1985;40(5):257-9.

11. Wolitzky-Taylor KB, Castriotta N, Lenze, EJ, Stanley MA, Craske MG. Anxiety disorders in older adults: a comprehensive review. Depress Anxiety. 2010;27(2):190-211.

12. Bogner HR, Gallo JJ, Swartz KL, Ford DE. Anxiety disorders and disability secondary to urinary incontinence among adults over age 50. Int J Psychiatry Med. 2002;32(2):141-54.

13. Felde G, Bjelland I, Hunskaar S. Anxiety and depression associated with incontinence in middle-aged women: a large Norwegian crosssectional study. Int Urogynecol J. 2012;23(3):299-306.

14. Acquadro C, Kopp Z, Coyne KS, Corcos J, Tubaro A, Choo MS, et al. Translating overactive bladder questionnaires in 14 languages. Urology. 2005;67(3):536-40.

15. Giavoni A, Melo GF, Parente I, Dantas G. Elaboração e validação da Escala de Depressão para Idosos. Cad Saúde Pública. 2008;24(5):975-82.

16. Irwin DE, Milsom I, Hunskaar S, Reilly K, Kopp Z, Herschorn S, et al. Population-based survey of urinary incontinence, overactive bladder, and other lower urinary tract symptoms in five countries: results of the EPIC study. Eur Urol. 2006;50(6):1306-14.

17. Moreira ED Jr, Neves RC, Fernandes Neto A, Duarte FG, Moreira $\mathrm{TL}$, Lobo CF, et al. A population-based survey of lower urinary tract symptoms (LUTS) and symptom-specific bother: results from the Brazilian LUTS epidemiology study (BLUES). World J Urol. 2013;31 (6): 1451-8.

18. Sexton CC, Coyne KS, Thompson C, Bavendam T, Chen $\mathrm{Cl}$, Markland A. Prevalence and effect on health-related quality of life of overactive bladder in older Americans: results from the epidemiology of lower urinary tract symptoms study. J Am Geriatr Soc. 2011 ; 59(8): 1465-70.

19. Oliveira E, Lozinsky AC, Palos CC, Ribeiro DM, Souza AM, Barbosa CP. Influência do índice de massa corporal na incontinência urinária feminina. Rev Bras Ginecol Obstet. 2010;32(9):454-8.

20. Mishra GD, Hardy R, Cardozo L, Kuh D. Body weight through adult life and risk of urinary incontinence in middle-aged women: results from a British prospective cohort. Int J Obes (Lond). 2008;32(9): 1415-22.

21. Hansen BB, Svare J, Viktrup L, Jørgensen T, Lose G. Urinary incontinence during pregnancy and 1 year after delivery in primiparous women compared with a control group of nulliparous women. Neurourol Urodyn. 2012;31 (4):475-80.

22. Rortveit G, Daltveit AK, Hannestad YS, Hunskaar S; Norwegian EPINCONT Study. Urinary incontinence after vaginal delivery or cesarean section. N Engl J Med. 2003;348(10):900-7.

23. Mehta KM, Simonsick EM, Penninx BW, Schulz R, Rubin SM, Satterfield $S$, et al. Prevalence and correlates of anxiety symptoms in well-functioning older adults: findings from the health aging and body composition study. J Am Geriatr Soc. 2003;51 (4):499-504.

24. Beekman AT, Bremmer MA, Deeg DJ, van Balkom AJ, Smit JH, de Beurs $E$, et al. Anxiety disorders in later life: a report from the Longitudinal Aging Study Amsterdam. Int J Geriatr Psychiatry. 1998; 13(10):717-26.

25. Lim JR, Bak CW, Lee JB. Comparison of anxiety between patients with mixed incontinence and those with stress urinary incontinence. Scand J Urol Nephrol. 2007;41(5):403-6.

26. Knight S, LuftJ, Nakagawa S, Katzman WB. Comparisons of pelvic floor muscle performance, anxiety, quality of life and life stress in women with dry overactive bladder compared with asymptomatic women. BJU Int. 2012; 109(1 1):1685-9.

27. Perry S, McGrother CW, Turner K; Leicestershire MRC Incontinence Study Group. An investigation of the relationship between anxiety and depression and urge incontinence in women: development of a psychological model. Br J Health Psychol. 2006; 11 (Pt 3):463-82.

28. Henderson AS, Jorm AF, Korten AE, Jacomb P, Christensen $H$, Rodgers B. Symptoms of depression and anxiety during adult life: evidence for a decline in prevalence with age. Psychol Med. 1998;28(6): 1321-8.

29. Jorm AF. Does old age reduce the risk of anxiety and depression? A review of epidemiological studies across the adult life span. Psychol Med. 2000;30(1):11-22. 